\title{
EDITORIAL
}

\section{Research into the dementias ${ }^{1}$}

Attempting to establish priorities in medical research is usually a thankless exercise. Research prospers through personal commitment rather than collectively perceived need, and individual inspiration when available stands to achieve immensely more than carefully conceived scientific policies. There is a place, nonetheless, for drawing attention to neglected areas, stressing problems of outstanding need, and highlighting organizational blocks and barriers which may be impeding the natural development of a subject. Such issues are particularly germane when several disciplines have a central part to play in achieving progress and must work in close liaison with one another.

These may be considered among the main reasons for focusing attention on biomedical research in the dementias as the Medical Research Council has done in a recent report (Medical Research Council, 1977). The pamphlet aims to chart problem areas and avenues for useful research into this distressing class of illnesses, and to consider strategies for facilitating enquiries by clinicians and laboratory workers.

The need for such work is abundantly obvious. The presenile dementias are major tragedies; and the senile dementias so ubiquitous that they threaten constantly to overwhelm the treatment and caring services. Yet these mysterious conditions have traditionally been by-passed by medical research in favour of topics more immediately attractive. Despite the lure of a visible pathology, the fundamentals of causation have only sporadically been explored, and the rich clinical material everywhere available has usually been seriously neglected. Much of the blame doubtless lies in the parallels that have been drawn between the common forms of dementia in the elderly and the processes of 'natural senescence' - sterile conceptions of 'abiotrophy' or 'premature ageing' have served to deflect endeavour, and only recently have more hopeful and testable hypotheses begun to be explored. Patterns of patient care have further conspired to impede progress. Responsibility is shared among several clinical disciplines. Patients tend to be cared for in units remote from teaching hospitals and academic centres so that opportunities for intensive study become immensely hard to achieve. Demarcation disputes, and the business of trying to cope, are more liable to surround the aged dement than processes of scientific enquiry.

Need and neglect alone, however, cannot promise a useful yield. Before accepting the dementias as suitable targets for intensive research we will need more encouragement to proceed. Thus, we may note that strong reasons can be marshalled against the simple ageing hypothesis. Epidemiological evidence shows that, even in extreme old age, the majority of persons retain their intellectual competence. It now seems likely that parenchymatous senile dementia is analogous in virtually all respects to Alzheimer's disease occurring at a very much younger age. A pathologically accelerated ageing process may indeed be involved, but the pathogenic factor could be toxic, biochemical or quite other in nature.

Moreover, we have witnessed examples of what may come to light when other 'degenerative' conditions are studied by modern techniques of biological enquiry. Parkinson's disease now has not only a respectable biochemical basis but a reasonably effective replacement therapy. CreutzfeldtJakob disease, itself traditionally included among the presenile dementias, has firmly joined the ranks of transmissible, and presumably agent-mediated, disorders. Attention therefore naturally turns towards attempts at unravelling the basis of the Alzheimer type of dementia, by far the commonest of the primary dementing illnesses. A cursory survey shows no dearth of avenues for study.

\footnotetext{
1 Address for correspondence: Dr W. A. Lishman, Institute of Psychiatry, De Crespigny Park, Denmark Hill, London
} SES 8 AF. 
Quantitative histology, biochemistry and experimental pathology have obvious parts to play; histochemistry, immunology and cytology are also implicated.

The traditionally static techniques of neuropathology are being supplemented by more dynamic conceptions and a more discriminating approach to the meaning of long-hallowed changes. A main task is to determine what are the significant tissue elements involved in the disease and how far these diverge from age-dependent changes. The degree of development of senile plaques, for example, has proved to correlate closely with the severity of the dementing process (Blessed et al. 1968; Tomlinson et al. 1970). But it is far from clear whether neuronal loss itself is so related, or indeed whether it is significantly more advanced in dementia than in age-matched controls. Careful cell (and synapse) counting by automated techniques can hope to clarify this issue and help decide whether or not we are dealing with a primarily neuronal disease. The phenomena represented by the neurofibrillary tangles in cell bodies and the senile plaques are also intriguing. Do the tangles embarrass cell function and axoplasmic transport? What is the origin of the plaques? Senile plaques consist of damaged neuritic terminals along with the formation of amyloid. Their frequent proximity to blood vessels and their amyloid content could betray a metabolic or immunological origin, with degeneration starting at the periphery of the neurone and spreading back to involve the cell bodies later. The demonstration that plaques can be induced in animals by infecting mice with the scrapie agent (Wisniewski et al. 1975) sharpens the need to gain further clarity on such issues.

Biochemical analysis of brain tissue provides a complementary approach. The discovery that a wide range of reliable neurochemical results can be obtained on autopsy material has led to the urgent need for establishing 'brain banks' which could greatly facilitate enquiries. Findings to date include loss of a specific brain protein (neuronin S-6) in the cortex (Bowen et al. 1973), and evidence that tangle-bearing neurones contain a new protein of abnormal type (Iqbal et al. 1974). A report of increased aluminium content in the brain in Alzheimer's disease is particularly intriguing (Crapper et al. 1973), since aluminium is known experimentally to be capable of inducing a form of neurofibrillary change in animals.

By far the most promising biochemical approach, however, is the study of enzymes involved in synaptic transmission. This reflects the functional competence of the elements which remain, and allows a search for selective loss in functional subsystems. Following the leads obtained in Huntington's chorea, of reduced GABA and glutamic acid decarboxylase in the basal ganglia (Perry $e t$ al. 1973; Bird \& Iversen, 1974), equivalent studies are now the focus of interest in presenile and senile dementia of the Alzheimer type. Investigations from several centres are combining to suggest a widespread deficiency in the cholinergic system, affecting many parts of the cortex and the hippocampus severely (Davies, 1977; Perry et al. 1977; Spillane et al. 1977; White et al. 1977). The enzymes responsible for the synthesis of acetylcholine (choline acetyl transferase) and for its degradation (acetylcholinesterase) have been found to be remarkably deficient, while the density of receptor binding sites appears to remain relatively normal, implying that replacement therapy may conceivably be effective. Such findings will, of course, require substantiation. Opportunities for artefacts are numerous - the agonal state of the patient, the procedures used prior to collection of samples, even the time of day of death are variables to be monitored closely. The cholinergic deficiencies may be only one of many interacting biochemical abnormalities. Nevertheless, trials of choline or its analogues, or other means of potentiating cholinergic mechanisms, would seem well justified and are already under way.

The established transmissibility of Creutzfeldt-Jakob disease, and growing awareness of "slow viruses' in relation to other neurological diseases, naturally raises the possibility that these too may be implicated in Alzheimer's/senile dementia. The evidence so far is, however, slender. Traub et al. (1977) review the experience to date from Gajdusek's laboratory. Out of 35 cases of Alzheimer's disease, 3 have transmitted to experimental animals. All, however, have produced on transmission the picture of spongiform encephalopathy which is one of the main characteristics of CreutzfeldtJakob disease; they do not produce the histological picture of Alzheimer's disease. Two were examples of the rare familial variant of Alzheimer's dementia and all were atypical in one way or another. There is also the possibility that the Creutzfeldt-Jakob agent may sometimes have occurred 
as a secondary pathogen in a brain already damaged by Alzheimer's disease. Again the area is one for continuing vigilance. Quite apart from any potential treatment outcome, it will be important to learn whether risk attaches to cortical biopsies in the general run of demented patients. A considerable scare has already been raised by evidence of surgical transmission of the Creutzfeldt-Jakob agent - first by corneal transplant in one case (Duffy et al. 1974), and more recently by the insertion of possibly infected silver electrodes into the brains of 2 young epileptic patients (Bernoulli et al. 1977).

The above are but examples of several lines of approach to the fundamentals of causation. It would be tempting to pin one's hopes on a few such areas alone and endow them with special priority for the investment of resources. Such a course of action might conceivably pay off if the gods were willing. But the field is so much on the threshold of discoveries and so replete with uncertainties that it would seem wise to keep several options open. Thus, the MRC report has recognized the need for encouraging a broad range of research enterprises, at least until such time as developments tip the scales in one direction or another.

Meanwhile clinicians, including clinical psychologists, have much to do. Diagnostic practices require continuing attention, nosology badly needs refinement, and treatment approaches could even now be extended. Surveys have shown the considerable yield of treatable pathologies when various populations of patients with the syndrome of dementia are comprehensively screened. Marsden \& Harrison (1972) found that $15 \%$ of 106 patients admitted to hospital with presumptive diagnoses of presenile or senile dementia had conditions amenable to treatment. Smith et al. (1976) estimated the figure at $20 \%$. Psychiatric conditions, especially depressive illness and severe neurotic disorders, can constitute a substantial source of error, as witnessed by follow-up studies of patients diagnosed as suffering from presenile dementia in psychiatric units (Nott \& Fleminger, 1975; Ron et al. 1978). The significance and the measurement of cerebral atrophy, in different age groups and in a variety of settings, needs thorough reappraisal, and computerized axial tomography is now at hand to allow this to be done.

Nosological confusions are rife and present major barriers to other areas of research. The distinctions during life between arteriopathic and parenchymatous forms of dementia are still far from certain, likewise distinctions between several subvarieties of the latter. The status of 'simple' presenile dementia has not been resolved; and parenchymatous senile dementia may yet prove to consist of more than one pathological entity. The requirements here are clear-cut - follow-up of adequate numbers of patients, studied intensively during life, then with full neuropathological and neurochemical examination after death. The further key question of the precise extent of the distinctions between dementia and 'normal' senescence will almost certainly require longitudinal community surveys of the elderly, so that early patterns of cognitive failure can be charted and followed with time. These latter enterprises would have an additional value in allowing comprehensive assessment of antecedents, precipitants, and the role of somatic pathologies in relation to dementia. Nosological groundwork of this nature may seem relatively unexciting, but we shall ignore such basic matters at great cost. A firm nosology would bring multiple lasting benefits - in allowing the discernment of clinical associations of the various disorders, clarifying the picture of genetics, speeding the pay-off from laboratory work, and streamlining trials of treatment.

Treatment is unfortunately the poor relation in most discussions of the primary dementias. Of the numerous substances claimed to improve cognitive functioning, whether by improved blood flow or enhanced cell metabolism, none appear to be truly useful. Trials may show slight measurable gains, chiefly in social functioning, but this can often be obtained by the sensitive use of standard psychotropic medication. It may be expected, however, that offshoots of the biochemical developments mentioned above will burgeon, and the pharmaceutical industry is no doubt watching such matters closely. It would seem a sound investment now to devote considerable energy into improving means of monitoring the progress of patients with dementia. We need clearer delineation of core areas of disability, and careful selection of the parameters and methods most suited for measuring change. Conventional psychometric tests are clearly unsatisfactory for the purpose. Measures of information processing or simple tests of mental speed and flexibility could perhaps prove far superior.

There is abundant room too for working towards more skilful use of existing methods of manage- 
ment. Demented patients survive for many years, both in the community and in institutions; we must aim to promote the optimum quality of life that is possible for them, and to ease the burden on relatives, attendants and resources. The determinants of key symptoms such as restlessness, for example, could repay detailed study, likewise psychosocial means for delaying the downward curve to total dependence. There are encouraging indications that lee-way exists at many stages of the disorder for promoting the optimum use of residual functions, avoiding confrontations with failure, and helping the patient to cope with his own diminishing resources. Systematic research is needed to show what types of disability respond best and to what particular forms of psychological and social intervention. Miller (1977) has drawn together the scattered evidence on such matters, and on the value that could accrue from devising supportive 'prosthetic' environments. Health services research is also extensively implicated. Evaluation of patterns and models of care, and acceptance that several such models are needed, will be an essential prelude to more rational and satisfactory services.

Research into the dementias is clearly a multi-faceted enterprise. Both fundamental and applied components require to be carefully nurtured, and the former perhaps need very specially to be safeguarded. It is sobering to think how difficult it would have been, a decade or two ago, to write in much detail about such matters. It will be interesting, a decade from now, to see whether present aspirations have proved illusory, or whether substantial advances will, in fact, have been achieved.

W. A. LISHMAN

\section{REFERENCES}

Bernoulli, C., Siegfried, J., Baumgartner, G., Regli, F., Rabinowicz, T., Gajdusek, D. C. \& Gibbs, C. J. (1977). Danger of accidental person-to-person transmission of Creutzfeldt-Jakob disease by surgery. Lancet i, 478-479.

Bird, E. D. \& Iversen, L. L. (1974). Huntington's chorea post-mortem measurement of glutamic acid decarboxylase, choline acetyltransferase and dopamine in basal ganglia. Brain 97, 457-472.

Blessed, G., Tomlinson, B. E. \& Roth, M. (1968). The association between quantitative measures of dementia and of senile change in the cerebral grey matter of elderly subjects. British Journal of Psychiatry 114, 797-811.

Bowen, D. M., Smith, C. B. \& Davison, A. N. (1973). Molecular changes in senile dementia. Brain 96, 849-856.

Crapper, D. R., Krishnan, S. S. \& Dalton, A. J. (1973). Brain aluminium distribution in Alzheimer's disease and experimental neurofibrillary degeneration. Science 180 , 511-513.

Davies, P. (1977). Cholinergic mechanisms in Alzheimer's disease. British Journal of Psychiatry 131, 318-319.

Duffy, P., Wolf, J., Collins, G., De Voe, A. G., Streeten, B. \& Cowen, D. (1974). Possible person-to-person transmission of Creutzfeldt-Jakob disease. New England Journal of Medicine 290, 692-693.

Iqbal, K., Wisniewski, H. M., Shelanski, M. L., Brostoff, S., Liwnicz, B. H. \& Terry, R. D. (1974). Protein changes in senile dementia. Brain Research 77, 337-343.

Marsden, C. D. \& Harrison, M. J. G. (1972). Outcome of investigation of patients with presenile dementia. British Medical Journal ii, 249-252.

Medical Research Council (1977). Senile and Presenile Dementias. A Report of the MRC Subcommittee, compiled by W. A. Lishman. Medical Research Council: London.

Miller, E. (1977). Abnormal Ageing: The Psychology of Senile and Presenile Dementia. Wiley: London.
Nott, P. N. \& Fleminger, J. J. (1975). Presenile dementia: the difficulties of early diagnosis. Acta Psychiatrica Scandinavica 51, 210-217.

Perry, E. K., Gibson, P. H., Blessed, G., Perry, R. H. \& Tomlinson, B. E. (1977). Neurotransmitter enzyme abnormalities in senile dementia. Journal of the Neurological Sciences 34, 247-265.

Perry, T. L., Hansen, S. \& Kloster, M. (1973). Huntington's chorea: deficiency of $\gamma$-aminobutyric acid in brain. New England Journal of Medicine 288, 337-342.

Ron, M. A., Toone, B. K., Garralda, E. \& Lishman, W. A. (1978). Diagnostic accuracy in presenile dementia (Submitted for publication.)

Smith, J. S., Kiloh, L. G., Ratnavale, G. S. \& Grant, D. A. (1976). The investigation of dementia: the results in 100 consecutive admissions. Medical Journal of Australia 2, 403-405.

Spillane, J. A., White, P., Goodhardt, M. J., Flack, R. H. A., Bowen, D. M. \& Davison, A. N. (1977). Selective vulnerability of neurones in organic dementia. Nature 266, 558559.

Tomlinson, B. E., Blessed, G. \& Roth, M. (1970). Observations on the brains of demented old people. Journal of the Neurological Sciences 11, 205-242.

Traub, R., Gajdusek, D. C. \& Gibbs, C. J. (1977). Transmissible virus dementia: the relation of transmissible spongiform encephalopathy to Creutzfeldt-Jakob disease. In Aging and Dementia (ed. W. Lynn Smith and M. Kinsbourne), ch. S. SP Books Division of Spectrum Publications Inc: New York.

White, P., Hiley, C. R., Goodhardt, M. J., Carrasco, L. H., Keet, J. P., Williams, I. E. I. \& Bowen, D. M. (1977). Neocortical cholinergic neurones in elderly people. Lancet i, 668-669.

Wisniewski, H. M., Bruce, M. E. \& Fraser, H. (1975). Infectious aetiology of neuritic (senile) plaques in mice. Science 190, 1108-1110. 